\title{
CORRIGENDUM
}

doi:10.1038/nature08353

\section{Generation of pluripotent stem cells from adult human testis}

Sabine Conrad, Markus Renninger, Jörg Hennenlotter, Tina Wiesner, Lothar Just, Michael Bonin, Wilhelm Aicher, Hans-Jörg Bühring,

Ulrich Mattheus, Andreas Mack, Hans-Joachim Wagner,

Stephen Minger, Matthias Matzkies, Michael Reppel,

Jürgen Hescheler, Karl-Dietrich Sievert, Arnulf Stenzl

$\&$ Thomas Skutella

Nature 456, 344-349 (2008)

In this Letter, we omitted to disclose that the original patient consent forms to collect the material used to derive the pluripotent stem cells precluded distribution to third parties, as ruled on 8 December 2008, by the Ethics Commission of the School of Medicine and University Hospital Tübingen. Moreover, the Commission also ruled that the materials used to generate the lines were obtained from individuals who had signed consent forms that did not allow retention of the cells in culture for more than 3 years. We have now received broader consent of a few individuals permitting distribution of cells. These cells will be cultivated, and after quality tests they will be distributed to other scientists. The other individuals whose tissues were used in the study have opted for the terms of the initial consent, and thus their cell lines will be destroyed when the 3 -year period runs out. We are now using the described protocols to generate new cell lines from individuals who have given explicit consent for distribution of lines to scientists. 